\title{
PRESENCIA DE Staphylococcus aureus METICILINA- RESISTENTES EN QUESO DOBLE CREMA ARTESANAL
}

\section{PRESENCE OF METHICILLIN-RESISTANT Staphylococcus aureus INARTISAN DOUBLE CREAM CHEESE}

\author{
Fanny Herrera A. ${ }^{*}$, Jesús Santos B. ${ }^{2}$ \\ ${ }^{1}$ Microbióloga, Ph.D. Profesora Titular. Universidad de Pamplona, Facultad de Ciencias Básicas, Departamento de \\ Microbiología, Grupo de Investigación en Microbiología y Biotecnología (GIMBIO). Ciudad Universitaria, Pamplona, Norte de \\ Santander, Colombia, e-mail: fannyh@unipamplona.edu.co; ${ }^{2}$ Biólogo. Ph.D. Profesor Titular de Universidad. Universidad \\ de León, Facultad de Veterinaria, Departamento de Higiene y Tecnología de los Alimentos. Campus de Vegazana, A.A. Nro. \\ 24071, León, España. *Correspondencia: fannyh@unipamplona.edu.co
}

Rev. U.D.C.A Act. \& Div. Cient. 18(1): 29-37, Enero-Junio, 2015

\section{RESUMEN}

Staphylococcus aureus meticilina-resistente (MRSA) ha sido considerado como un patógeno limitado a infecciones nosocomiales, que además se puede transmitir por los alimentos. En este estudio, se analizaron 68 cepas de Staphylococcus, coagulasa positivas, aisladas a partir de 100 muestras de queso doble crema artesanal, elaborado en Pamplona (Colombia). Se determinó la prevalencia de los siguientes genes, mediante PCR: mecA, coa, tst y los correspondientes a las principales enterotoxinas, que puede producir esta bacteria. Se detectó el gen mecA, en el 18,2\% de cepas $S$. aureus, identificadas. Todas las cepas portaban el gen coa, con una muy baja heterogeneidad. Ninguna cepa evidenció la existencia del gen que codifica la toxina 1 del síndrome del shock tóxico (tst); en el $42 \%$ de las cepas MRSA, se estableció la existencia del gen, para la enterotoxina B. La presencia de cepas MRSA, en este estudio, debe ser considerada como un peligro potencial para la salud de los consumidores de queso crema artesanal, especialmente, para personas dentro del rango poblacional, propensas a contraer infecciones alimentarias, en quienes esta bacteria puede llegar ser letal. Se sugiere la implementación de las medidas necesarias para evitar la futura propagación de MRSA, a la población por los alimentos, haciendo énfasis en la implantación de Buenas Prácticas Higiénicas y en la supervisión de la correcta utilización de antibióticos.

Palabras clave: Enterotoxinas, mecA, resistencia antibiótico, producto lácteo.

\section{SUMMARY}

Methicillin-resistant Staphylococcus aureus is regarded as a pathogen limited to nosocomial infections, which can also be transmitted by food. In this study 68 Staphylococcus coagulase positive isolates obtained from 100 samples of artisan double cream cheese elaborated in Pamplona (Colombia) were analyzed. The presence of mecA and coa genes and the corresponding genes to the main staphylococcal enterotoxins was determined by PCR. mecA gene was detected in $18,2 \%$ of S.aureus strains analyzed. All isolates carried the coa gene with very low heterogeneity; no strain showed the existence of the gene that encodes the toxin 1 of the toxic shock syndrome; The enterotoxin $B$ gene was detected in $42 \%$ of the MRSA strains. The presence of MRSA strains in this study should be considered a potential health risk for consumers, especially vulnerable sections of the population who are prone to get foodborne infections where this bacteria can be lethal. The implementation of measures to prevent the spread of MRSA by food to the population, with particular emphasis in the implementation of Good Hygienic Practices and in the supervision of the correct use of antibiotics is suggested.

Key words: Enterotoxins, mecA, antibiotic resistance, dairy product.

\section{INTRODUCCIÓN}

Se considera a Staphylococcus aureus uno de los principales agentes causales de Enfermedades Transmitidas por los Alimentos (ETAs), en el mundo y el patógeno más frecuentemente asociado a quesos elaborados con leche 
cruda (Cretenet et al. 2011). En Colombia, S. aureus se encuentra entre los principales microorganismos que se declaran en la red de vigilancia de ETAs (Vanegas et al. 2008).

Staphylococcus aureus produce una gran variedad de factores de virulencia, entre ellos, la coagulasa, la toxina 1 del síndrome del shock tóxico (TSST-1) y las enterotoxinas estafilocócicas (SE). La coagulasa ocasiona la formación de una capa de fibrina alrededor del absceso estafilocócico, localizando la infección y protegiendo a la bacteria de la fagocitosis. La toxina 1 del síndrome del shock tóxico de $S$. aureus actúa como superantígeno, estimulando la liberación de varias citocinas, prostaglandinas y leucotrienos, los cuales, producen los signos y loa síntomas del síndrome, que son fiebre alta, dolor de cabeza, vómito, diarrea, mialgias (Herzer, 2001). Las enterotoxinas estafilocócicas (SE) provocan la intoxicación alimentaria; $S$. aureus produce cinco toxinas típicas: SEA, SEB, SEC, SED y SEE, las cuales, originan emesis en primates. Las enterotoxinas más frecuentes en brotes de ETAs son la ESA y la ESB (Pinchuk et al. 2010).

Además de los factores ya mencionados y de otros tantos que presenta S. aureus (Bustos et al. 2006), se tiene su acrecentada resistencia frente a los antibióticos. Desde su resistencia a la penicilina, en los años 40 , se introdujeron nuevos antibióticos $\beta$-lactámicos, estables a la acción de las penicilinasas, como la meticilina. Muy poco tiempo después, en 1960, se presentaron las primeras cepas resistentes, denominadas MRSA (Methicillyn Resistant S. aureus); a partir de entonces, se han aislado cepas de MRSA, en todo el mundo; su diversidad genética y capacidad de adquirir genes exógenos por medio de plásmidos, secuencias de inserción o transposones, le permite a esta bacteria adaptarse fácilmente a condiciones ambientales cambiantes y modular su patogenicidad (Moellering, 2012).

Las infecciones provocadas por las cepas MRSA, inicialmente, se limitaban al ambiente hospitalario (HAMRSA). Posteriormente, en los 90, aparecieron los primeros reportes por infecciones adquiridas en la comunidad (CAMRSA), en las cuales, no existen, aparentemente, en el individuo factores de riesgo, relacionados con atención hospitalaria. El tercer tipo de emergencia se ha asociado con infecciones en animales de abasto vivos, denominados LAMRSA (Livestock-associated MRSA), lográndose aislar MRSA en cerdos (Voss et al. 2005), en pollos (Fessler et al. 2011), en ganado vacuno y ovejas (Fessler et al. 2012), entre otros.

En todo el mundo, se ha detectado la presencia de MRSA en diversos alimentos de origen animal; concretamente, en carne de vacuno, las prevalencias son muy variadas. En Holanda, un estudio encontró MRSA en el 10,6\% de muestras de carne de res y, en el 15,2\%, de muestras de ternera (de Boer et al.
2009). Weese et al. (2010) detectaron once cepas MRSA, en 198 muestras de carne molida, originarias de Canadá. En Irán, se aislaron MRSA, a partir del 89,1\%, de muestras positivas para S. aureus, aisladas de hamburguesas (Shahraz et al. 2012). En Georgia, Estados Unidos de América (EUA), se obtuvo una prevalencia del 4,0\%, en cárnicos de res al detal (Jackson et al. 2013). En leche de vaca, la presencia de MRSA, se ha asociado, de forma general, a la producción de mastitis en vacas; en Bélgica, se identificaron 9,3\% de cepas aisladas de muestras de leche con mastitis, como MRSA (Vanderhaeghen et al. 2010). Asimismo, Haran et al. (2012), aislaron dos cepas MRSA, a partir de 150 muestras de leche cruda, en Minnesota (EUA). En Italia, Normanno et al. (2007) identificaron cuatro MRSA, de 160 cepas de $S$. aureus, a partir de muestras de leche.

El más reciente tipo de emergencia ocasionada por los MRSA tiene que ver con la producción de enfermedad en el hombre, por el consumo de alimentos (FBA-MRSA, FoodBorne Associated-MRSA). Hasta la fecha, se han reportado dos brotes de origen alimentario por MRSA, siendo el origen, manipuladores infectados (Jones et al. 2002; Kluytmans et al. 1995). En la actualidad, existe controversia respecto a las verdaderas implicaciones de este tipo de emergencia bacteriana en la salud pública; sin embargo, se ha demostrado el vinculo epidemiológico existente entre la presencia de cepas MRSA en heces de pacientes con diarrea con cepas aisladas en muestras de carne cruda, comercializada en la misma región, de donde procedían los pacientes, sugiriendo que la carne puede determinar la presencia de MRSA y ocasionar enfermedad en la comunidad y, de esta manera, evidenciar que los alimentos puedan ser una fuente de estas cepas en la población (Ogata et al. 2012).

Los MRSA pueden ocasionar una gran variedad de manifestaciones clínicas en el hombre, desde infecciones leves en la piel, bacteriemia, neumonía, endocarditis, síndrome del shock tóxico e, incluso, la muerte (Bustos et al. 2006).

Según el Centro de Control de Enfermedades de Europa (ECDC), en el 2011, la prevalencia de MRSA fue superior al $25 \%$, en ocho de los países que reportan a esta entidad, Naciones ubicadas, principalmente, en el sureste de ese continente (ECDC, 2013). Otros datos han establecido que los MRSA han enfermado más de 150.000 personas, en el 2010, en la Unión Europea (Doyle et al. 2012). En EUA, de acuerdo con el Centro de Control de Enfermedades (CDC), el número de casos ocasionados por MRSA, incluyendo CA y HA, fue de 75.309, para el 2012 (CDC, 2012). En países, como Korea, la tasa de resistencia a la meticilina entre cepas S. aureus, de origen humano, es superior al 50\% (Moon et al. 2007). 
En Colombia, los datos existentes evidencian que los casos de CA-MRSA se incrementaron de 1,0\%, en el 2001 a 5,4\%, en el 2006 (Guzmán-Blanco et al. 2009); asimismo, se ha encontrado una prevalencia de MRSA en hospitales de tercer nivel, del 45\% (Mejía et al. 2010).

Los objetivos de este estudio fueron determinar la prevalencia de cepas MRSA en muestras de queso doble crema artesanal, elaborado en Pamplona (Colombia) y establecer la presencia de genes que codifican factores de virulencia en las cepas aisladas.

\section{MATERIALES Y MÉTODOS}

Cepas: Se analizaron 68 cepas de Staphylococcus coagulasa positivas aisladas, a partir de 100 muestras de queso doble crema, elaborado en Pamplona (Colombia). Estas cepas fueron aisladas, empleando el método tradicional, utilizando agar Baird Parker y realizando la prueba de la coagulasa, según la NTC 4779 (2007). Se realizaron, además, las pruebas de tinción de Gram y catalasa.

\section{Identificación fenotípica de las cepas}

Fermentación de la maltosa: A partir de cultivos de cada cepa crecidos en caldo BHI (Brain Heart Infusion, Oxoid), se inocularon $20 \mu \mathrm{L}$ en caldo base púrpura al $1,0 \%$ de maltosa. Se realizó la incubación a $37^{\circ} \mathrm{C}$, durante 24 h; se consideró como positivo el cambio de color del medio hacia amarillo.

Factor de aglutinación: Fue adicionada una gota del reactivo de prueba sobre la tarjeta de reacción Staphaurex (Remel). Por medio de un asa, se tomaron de 1-3 colonias crecidas en agar TSA (Tryptone Soya Agar, Oxoid). Se observó la aparición de aglutinación máximo 20 seg, luego de la adición del reactivo.

Actividad termonucleasa: Se sometieron los cultivos de cada cepa crecidos en caldo BHI, a baño serológico, con agua hirviendo durante $15 \mathrm{~min}$. Posteriormente, se inocularon en spot sobre agar ADN-azul de toluidina (Oxoid) e incubaron a $37^{\circ} \mathrm{C} / 24 \mathrm{~h}$. La aparición de una zona rosa alrededor de las colonias indicó la presencia de actividad termonucleasa.

Coagulación del plasma de conejo: Fueron adicionados $0,5 \mathrm{~mL}$ de un cultivo overnight de cada cepa en caldo $\mathrm{BHI}$, a tubos de $10 \mathrm{~mm}$ de diámetro interno, conteniendo $0,5 \mathrm{~mL}$ de plasma de conejo hidratado (Biomerieux), incubando a $37^{\circ} \mathrm{C}$. Se realizó la lectura luego de $6 \mathrm{~h}$, considerando como positivas, las cepas que evidenciaron un coágulo firme adherido a las paredes del tubo.

Degradación del fibrinógeno: A partir de cada cepa mantenida en TSA, se realizó una inoculación en spot en agar Baird
Parker, suplementado con fibrinógeno (Bioser), incubando a $37^{\circ} \mathrm{C}$, por 24 horas. Se consideraron positivas aquellas cepas que, luego del periodo de incubación, formaban colonias brillantes, convexas, de color gris oscuro a negro, con una zona opaca alrededor de las colonias.

\section{Presencia de genes de virulencia en las cepas}

Detección de genes por PCR: Se analizó la presencia de los siguientes genes: mecA, coa, sea, seb, sec, sed, see y tst, que codifican, respectivamente: resistencia a la meticilina, coagulasa, enterotoxinas $\mathrm{A}$ a la $\mathrm{E}$ y la toxina del síndrome del shock tóxico. A partir de las cepas coagulasa positivas crecidas en caldo TSB (Caldo Tripticasa de Soja, Oxoid) e incubadas a $37^{\circ} \mathrm{C}$, durante 24 horas, se transfirió $1,0 \mathrm{~mL}$, centrifugando a $13,000 \times \mathrm{g} / 3 \mathrm{~min}$. Posteriormente, se adicionaron $200 \mu \mathrm{L}$ de Chelex-100 (Bio-Rad), resuspendiendo el sedimento completamente e incubando a $56^{\circ} \mathrm{C}$, por 30 min. Se agitó cada tubo durante 10 segundos; luego, se sometió cada tubo a $100^{\circ} \mathrm{C}$, durante 8 minutos; nuevamente, se agitó cada tubo y, finalmente, se centrifugó a 13,000 × g/3min. Se cuantificó la concentración de ADN, empleando un Espectrofotómetro-UV Q3000. Partiendo de $3 \mu \mathrm{L}$ del ADN (50ng/ $\mu \mathrm{L}$, aproximadamente), se llevó a cabo la PCR; para esto, se emplearon los pares de cebadores correspondientes para cada gen a una concentración de $25 \mathrm{mM}$ y un cóctel comercial, conteniendo Taq polimerasa, buffer, dNTPs y $\mathrm{Mg}^{+2}$ (5 PRIME). Fueron amplificados los diferentes genes en un equipo Mastercycler Personal. La secuencia de los cebadores empleados y la longitud de los amplificados, se muestran en la tabla 1 .

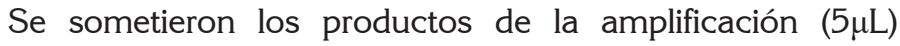
a electroforesis en gel de agarosa (Bio- Rad), al 1,0\% p/v a $100 \mathrm{~V}$, durante $1 \mathrm{~h}$. Se realizó la visualización mediante tinción con RedSafeTM (iNtRon Biotechnology), empleando un transiluminador de luz ultravioleta, Mini-Transiluminador y documentando con la aplicación del Digimage System, acoplado a una cámara digital Canon Power Shot G11.

\section{RESULTADOS Y DISCUSIÓN}

Identificación fenotípica de las cepas: El 97\% de las cepas, se identificaron como $S$. aureus, con base a la actividad lecitinasa en el agar Baird Parker, tinción de Gram, reacción de catalasa, reducción del telurito en el agar Baird Parker con RPF, pigmento amarillo en TSA y por su actividad maltosa, termonucleasa, factor de aglutinación y coagulación del plasma de conejo.

Presencia de genes que codifican factores de virulencia: Se detectó la presencia del gen mecA, en el 18,2\% de cepas S. aureus identificadas (Figura 1), correspondiendo a una prevalencia del 9,0\% en las muestras de queso analizadas 
Tabla 1. Genes, cebadores, temperaturas de hibridización y tamaños esperados de los amplicones empleados para determinar la presencia de genes, que codifican factores de virulencia, en cepas de Staphylococcus coagulasa positivos.

\begin{tabular}{|c|c|c|c|c|}
\hline Gen & Secuencia del Primer $\left(5^{\prime}\right.$ a $\left.3^{\prime}\right)$ & $\begin{array}{l}\text { Temperatura de } \\
\text { hibridación }\left({ }^{\circ} \mathrm{C}\right)\end{array}$ & $\begin{array}{l}\text { Longitud del } \\
\text { amplicón (pb) }\end{array}$ & Referencia \\
\hline mecA & $\begin{array}{l}\text { GCAATCGCTAAAGAACTAAG } \\
\text { GGGACCAACATAACCTAATA }\end{array}$ & 56 & 240 & Smyth et al. (2001) \\
\hline coa & $\begin{array}{l}\text { ATAGAGATGCTGGTACAGG } \\
\text { GCTTCCGATTGTTCGATGC }\end{array}$ & 57 & $547-840$ & Hookey et al. (1998) \\
\hline sea & $\begin{array}{c}\text { ACGATCAATTTTTACAGC } \\
\text { TGCATGTTTTCAGAGTTAATC }\end{array}$ & 56 & 544 & Rosec \& Gigaud (2002) \\
\hline seb & $\begin{array}{l}\text { GAATGATATTAATTCGCATC } \\
\text { TCTTTGTCGTAAGATAAACTTC }\end{array}$ & 55 & 416 & Rosec \& Gigaud (2002) \\
\hline sec & $\begin{array}{l}\text { GACATAAAAGCTAGGAATTT } \\
\text { AAATCGGATTAACATTATCCA }\end{array}$ & 56 & 257 & Rosec \& Gigaud (2002) \\
\hline sed & $\begin{array}{l}\text { TTACTAGTTTGGTAATATCTCCTT } \\
\text { CCACCATAACAATTAATGC }\end{array}$ & 58 & 334 & Rosec \& Gigaud (2002) \\
\hline see & $\begin{array}{l}\text { ATAGATAAAGTTAAAACAAGCAA } \\
\text { TAACTTACCGTGGACCC }\end{array}$ & 52 & 170 & Rosec \& Gigaud (2002) \\
\hline tst & $\begin{array}{l}\text { ACCССТGTTCССТTATCATC } \\
\text { TTTTCAGTATTTGTAACGCC }\end{array}$ & 57 & 326 & Mehrotra et al. (2000) \\
\hline
\end{tabular}

(Tabla 2). En estudios similares, Shanehbandi et al. (2014) detectaron este gen en el $21 \%$ de cepas de $S$. aureus aisladas de quesos tradicionales, en Irán. En Brasil, Fonseca et al. (2011) revelaron la presencia de cepas MRSA, en una muestra de queso tradicional. En Colombia, Vanegas et al. (2012) aislaron 3,0\% de MRSA, a partir de muestras de carne molida y crema de leche. Para nuestro conocimiento, este es el primer reporte de MRSA en queso en Colombia.

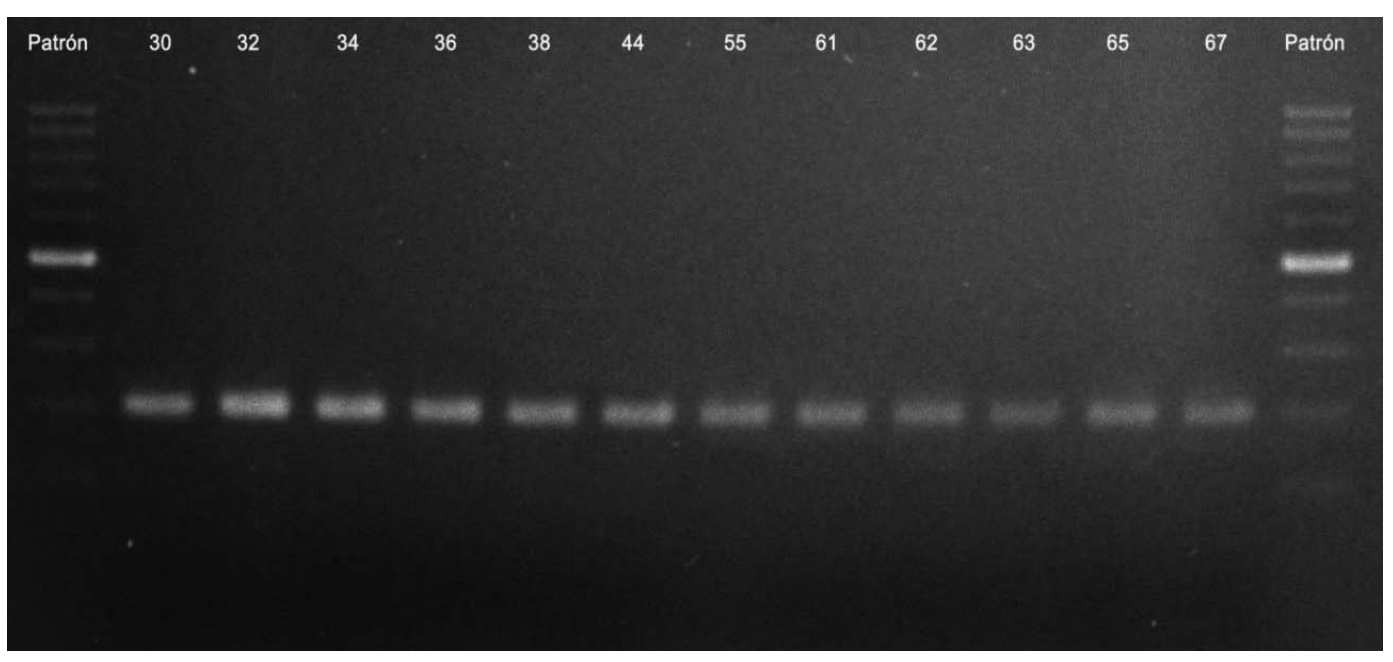

Figura 1. Presencia del gen mecA en cepas S. aureus aisladas, a partir de queso artesanal. El patrón de peso molecular está conformado por bandas de 100pb, cada una; la banda más intensa corresponde a 500pb. 
Tabla 2. Genes que codifican factores de virulencia presentes en las cepas MRSA analizadas.

\begin{tabular}{|c|c|c|c|c|}
\hline MUESTRA & CEPA & GEN mecA & TAMAÑO GEN coa & ESB \\
\hline 37 & 30 & POS & 573 & NEG \\
\hline 42 & 32 & POS & 583 & NEG \\
\hline 43 & 34 & POS & 593 & NEG \\
\hline 43 & 36 & POS & $796-567$ & NEG \\
\hline 44 & 38 & POS & 568 & NEG \\
\hline 50 & 44 & POS & 565 & NEG \\
\hline 61 & 55 & POS & 573 & POS \\
\hline 78 & 61 & POS & 571 & POS \\
\hline 78 & 62 & POS & 562 & POS \\
\hline 78 & 63 & POS & 563 & POS \\
\hline 82 & 65 & POS & 581 & 578 \\
\hline 84 & 67 & POS & & \\
\hline
\end{tabular}

La resistencia de $S$. aureus a la meticilina está conferida por el gen mecA, que codifica una proteína variante de unión a la penicilina (PBP), llamada PBP2a. Las PBPs, que se encuentran normalmente en la pared celular de la bacteria, se unen a la penicilina y previenen la síntesis de pared, ocasionando la muerte bacteriana; sin embargo, la PBP2a tiene una reducida afinidad por los antibióticos $\beta$-lactámicos, de tal manera, que continúa sintetizando peptidoglicano para la pared celular, aun cuando las PBP normales estén inhibidas por los antibióticos (Hiramatsu et al. 2001).

Todas las cepas MRSA portaban el gen coa; al determinar su tamaño, mediante la utilización del software GelAnalyzer, la variación del tamaño fue de 562 a 796pb (Tabla 2); En una de las cepas se obtuvieron dos amplicones, sugiriendo algún grado de diversidad genética entre cepas, procedentes de la misma muestra (Figura 2), hallazgo que debe ser confirmado por los autores, por medio de técnicas, como la Electroforesis en Gel de Campo Pulsado (PFGE).

Ninguna cepa evidenció la existencia del gen que codifica la toxina 1 del síndrome del shock tóxico (tst); resultados similares, se obtuvieron en muestras de productos cárnicos de pollo y de pavo (Fessler et al. 2011), en cepas aisladas de diferentes muestras, incluyendo carne y leche (Argudín et al. 2011) y en muestras de leche cruda (Haran et al. 2012), entre otros alimentos.

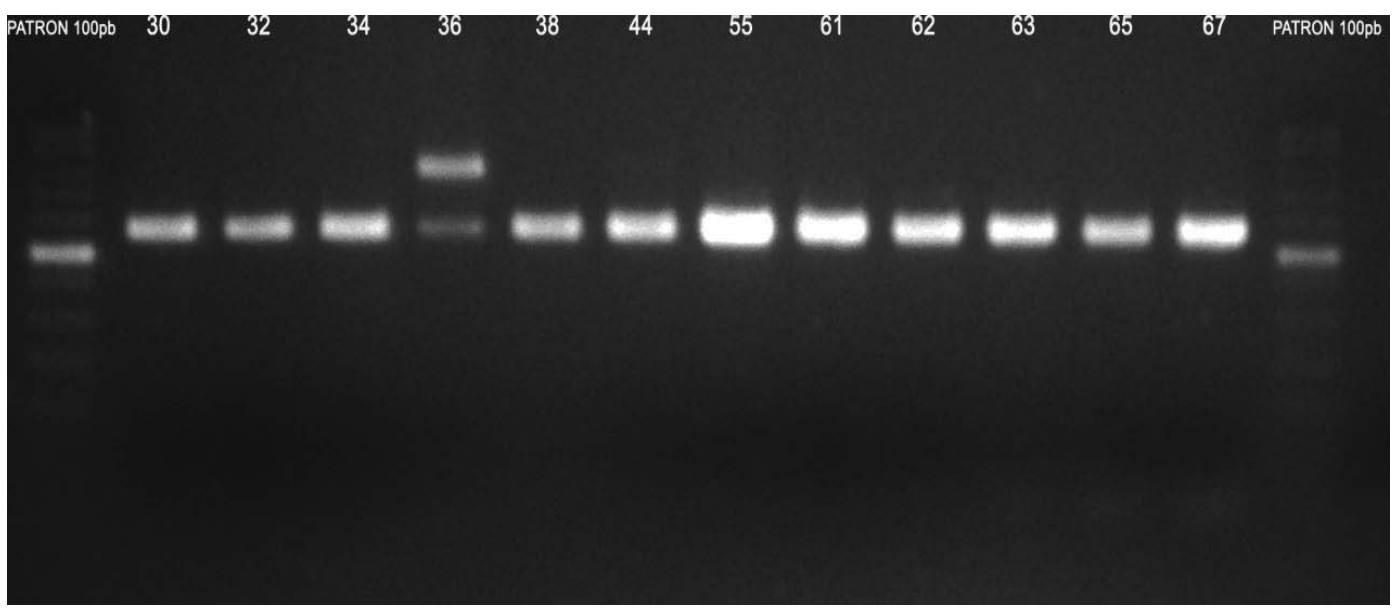

Figura 2. Amplificados del gen coa obtenidos para las cepas MRSA aisladas, a partir de queso artesanal. El patrón de peso molecular está conformado por bandas de 100pb, cada una; la banda más intensa corresponde a 500pb. 
En el $42 \%$ de las cepas MRSA, se detectó la presencia del gen, para la enterotoxina estafilocócica B (ESB) (Figura 3 ), correspondiendo a una prevalencia del 3,0\%, en las muestras, siendo el primer reporte, de esta enterotoxina en cepas MRSA, en quesos en Colombia (Tabla 2). Otros autores detectaron este gen, junto con el de otras enterotoxinas en cepas MRSA aisladas, a partir de leche cruda: Wang et al. (2014), a partir de muestras de leche cruda procedentes de China y Haran et al. (2012), en Minessota.
El hecho de detectar el gen para la ESB provee mayor evidencia para soportar que las cepas MRSA puedan estar involucradas en brotes de intoxicaciones alimentarias (Normanno et al. 2007).

Se han investigado dos brotes de origen alimentario por las cepas MRSA: Uno de ellos ocurrió en Tennessee, en 2000 (Jones et al. 2002), vinculado al consumo de ensalada de col, logrando detectar el mismo aislado, a partir de frotis

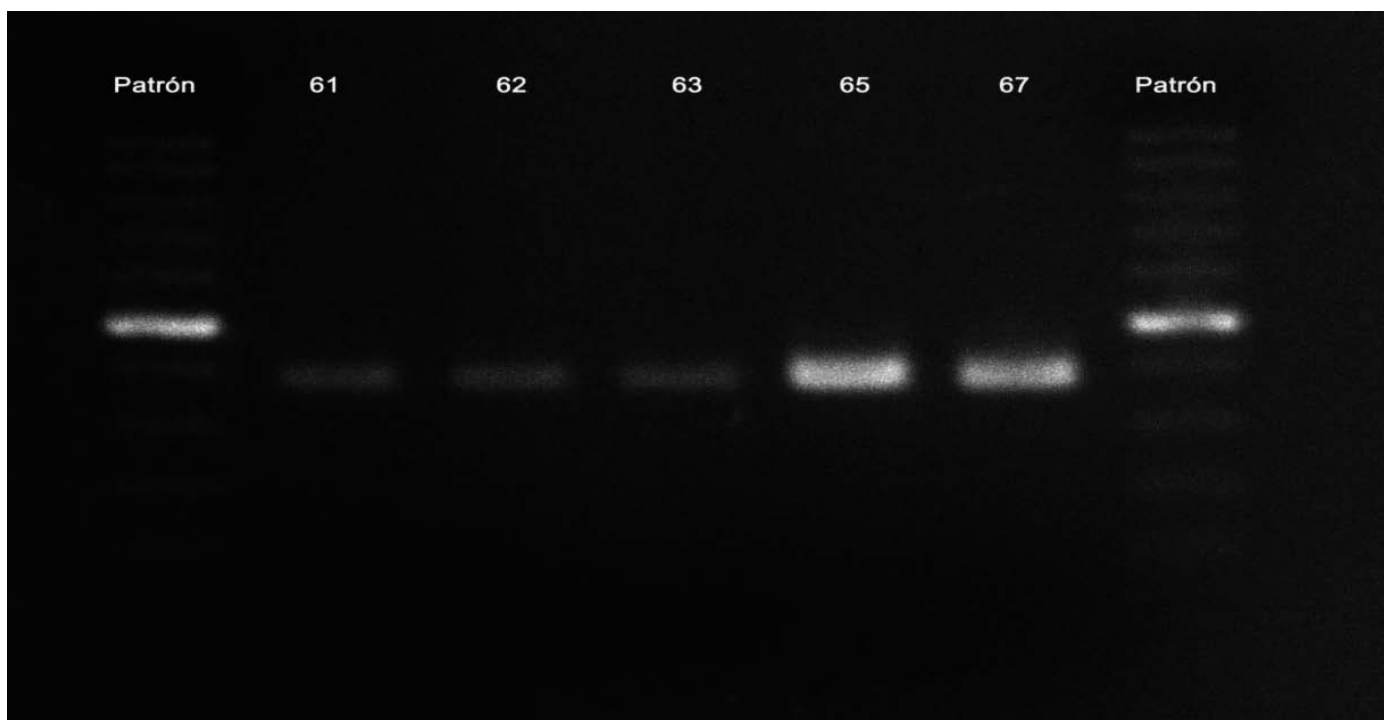

Figura 3. Presencia del gen esb en las cepas MRSA aisladas de queso artesanal. Patrón 100pb. El patrón de peso molecular está conformado por bandas de 100pb, cada una; la banda más intensa corresponde a 500pb.

de nariz de un manipulador. El otro brote, ocurrido en un hospital en Rotterdam, Holanda, afectó 27 pacientes y a 14 empleados de la unidad de cuidados intensivos, ocasionando cinco muertes. Los estudios epidemiológicos relacionaron a un empleado de esta unidad como la fuente del brote, quien contaminó un alimento ofrecido a los pacientes (Kluytmans et al. 1995). En estos brotes, se destaca a los portadores sanos, como vehículos importantes de cepas MRSA. A este respecto, Gorwitz et al. (2008) reportaron que $1,5 \%$ de la población en EUA, en el periodo 2003-2004, fue portadora de cepas MRSA, correspondiendo a 4.1 millones de personas, pudiendo convertirse en posibles fuentes de contaminación, sobre todo, si estas personas manipulan alimentos.

Es muy probable que el origen de la presencia de las cepas MRSA aisladas en las muestras de queso doble crema artesanal, producido en Pamplona, sean los manipuladores de este alimento. En un estudio realizado anteriormente por los autores, se lograron comprobar las deficientes condiciones higiénico-sanitarias de los manipuladores de este alimento, presentando, algunos de ellos, heridas y laceraciones en las manos, expuestas en contacto directo con el alimento y en quienes los recuentos de $S$. aureus, de frotis de manos, fueron elevados (Daza et al. 2013).

Otros factores que pueden aumentar la presencia de cepas MRSA en los alimentos de origen animal es el uso indiscriminado de antibióticos en veterinaria y los antibióticos adicionados en los piensos para los animales de abasto. Estos abusos inducen la selección de cepas resistentes y su posterior introducción en la cadena alimentaria (Intrakamhaeng et al. 2012; Moon et al. 2007).

Por todo lo anterior, es necesario capacitar a los manipuladores del queso doble crema artesanal elaborado en Pamplona, en Buenas Prácticas de Manufactura, labor que ya se ha iniciado 
y sugerir a las autoridades sanitarias gubernamentales para que se ejerza control sobre la utilización de antibióticos, tanto en explotaciones ganaderas así como en la comunidad en general.

Finalmente, es imprescindible realizar la caracterización genotípica de las cepas aisladas, con el fin de confirmar los resultados del presente trabajo.

En conclusión, se detectó una importante prevalencia de cepas MRSA en muestras de queso doble crema artesanal, en Pamplona, que debe ser considerada como un potencial riesgo para la salud de los consumidores, especialmente, para personas inmunocomprometidas y ancianos, en quienes esta bacteria puede ser letal.

Conflictos de intereses: El manuscrito fue preparado y revisado con la participación de los autores, quienes declaramos que no existe ningún conflicto de intereses, que ponga en riesgo la validez de los resultados presentados.

\section{BIBLIOGRAFÍA}

1. ARGUDÍN, M.; TENHAGEN, B.; FETSCH, A.; SACHSENRODER, J.; KASBOHRER, A.; SCHROETER, A.; HAMMERL, J.; HERTWIG, S.; HELMUTH, R.; BRÄUNIG, J.; MENDOZA, M.; APPEL, B.; RODICIO, M.; GUERRA, B. 2011. Virulence and resistance determinants of German Staphylococcus aureus ST398 isolates from nonhuman sources. Appl. Environ. Microbiol. 77(9):3052-60.

2. BUSTOS, J.; HAMDAN, A.; GUTIÉRREZ, M. 2006. Staphylococcus aureus: la reemergencia de un patógeno en la comunidad. Rev. Biomed. 17:287305.

3. CENTERS FOR DISEASE CONTROLAND PREVENTION -CDC-. 2012. Active Bacterial Core Surveillance Report, Emerging Infections Program Network, Methicillin-Resistant Staphylococcus aureus, 2012. Disponible desde Internet en: http:/www.cdc.gov/ abcs/reports-findings/survreports/mrsa12.pdf (con acceso el 21/10/2014).

4. CRETENET, M.; EVEN, S.; LE LOIR, Y. 2011. Unveiling Staphylococcus aureus enterotoxin production in dairy products: a review of recent advances to face new challenges. Dairy Sci. Technol. 91:127-150.

5. DAZA, A.; HERRERA, F.; NARANJO, A. 2013. Condiciones higiénico-sanitarias aplicadas en la elaboración de queso doble crema manufacturado en tres empresas de la provincia de Pamplona-Colombia. Bistua. 11(2):61-73.

6. DE BOER, E.; ZWARTKRUIS-NAHUIS, J.; WIT, B.; HUIJSDENS, X.; DE NEELING, A.; BOSCH, T.; VAN OOSTEROM, R.; VILA, A.; HEUVELINK, A. 2009. Prevalence of methicillin-resistant Staphylococcus aureus in meat. Inter. J. Food Microbiol. 134:52-56.

7. DOYLE, M.; HARTMANN, F.; LEE A. 2012. Methicillinresistant Staphylococci: implications for our food supply? Anim. Health Res. Rev. 13:157-180.

8. EUROPEAN CENTRE FOR DISEASE PREVENTION AND CONTROL -ECDC-. 2013. Annual Epidemiological Report 2013. Reporting on 2011 surveillance data and 2012 epidemic intelligence data. Stockholm. 2013. Disponible desde Internet en: http://www. google.es $/$ url?sa $=$ t\&rct $=\mathrm{j} \& \mathrm{q}=\&$ esrc $=\mathrm{s} \&$ source $=$ web\&cd $=1 \&$ ved $=0$ CCMQFjAA\&url $=$ http $\% 3 \mathrm{~A} \% 2 \mathrm{~F}$ \%2Fecdc.europa.eu\%2Fen\%2Fpublications\%2FPub lications\%2FAnnual-Epidemiological-Report-2013. pdf\&ei $=2$ HItVIOjJ-vmyQP0oYHwCQ\&usg $=$ AFQjC NFUvR21D1151O1MTI7XzvkJhiSWVw\&bvm =bv.76 477589,d.bGQ (con acceso el 21/10/2014).

9. FESSLER, A.; KADLEC, K.; HASSEL, M.; HAUSCHILD, T.; EIDAM, C.; EHRICHT, R.; MONECKE, S.; SCHWARZ, S. 2011. Characterization of methicillinresistant Staphylococcus aureus isolates from food and food products of poultry origin in Germany. Appl. Environ. Microbiol. 77(20):7151-7157.

10. FESSLER, A.T.; OLDE RIEKERINK, R.G.; ROTHKAMP, A.; KADLEC, K.; SAMPIMON, O.; LAM, T.; SCHWARZ, S. 2012. Characterization of methicillin-resistant Staphylococcus aureus CC398 obtained from humans and animals on dairy farms. Vet. Microbiol. 160(1-2):77-84.

11. FONSECA, C.; MATTE, M.; DROPA, M.; MAMIZUKA, E.; DE ALMEIDA, L.; LINCOPAN, N.; MATTE, G.; LEAL, P. 2011. Identification of Staphylococcus aureus carrying the mecA gene in ready-to-eat food products sold in Brazil. Foodborne Pathog Dis. 8(4):561-563.

12. GORWITZ, R.; KRUSZON-MORAN, D.; MCALLISTER, S.; MCQUILLAN, G.; MCDOUGAL, L.; FOSHEIM, G.; JENSEN, B.; KILLGORE, G.; TENOVER, F.; KUEHNERT, M. 2008. Changes in the prevalence of nasal colonization with Staphylococcus aureus in the United States, 2001-2004. J. Infect. Dis. 197(9):1226-1234. 
13. GUZMÁN-BLANCO, M.; MEJÍA, C.; ISTURIZ, R.; ALVAREZ, C.; BAVESTRELLO, L.; GOTUZZO, E.; LABARCA, J.; LUNA, C.; RODRÍGUEZ, E.; SALLES, M.; ZURITA, J.; SEAS, C. 2009. Epidemiology of meticillin-resistant Staphylococcus aureus (MRSA) in Latin America. Int. J. Antimicrob. Agents. 4:304308.

14. HARAN, K.; GODDEN, S.; BOXRUD, D.; JAWAHIR, S.; BENDER, J.; SREEVATSAN, S. 2012. Prevalence and characterization of Staphylococcus aureus, including methicillin-resistant Staphylococcus aureus, isolated from bulk tank milk from Minnesota dairy farms. J. Clin. Microbiol. 50:688-695.

15. HERZER, C. 2001. Toxic shock syndrome: broadening the differential diagnosis. J. Am. Board Fam. Pract. 14:131-136.

16. HIRAMATSU, K.; CUI, L.; KURODA, M.; ITO, T. 2001. The emergence and evolution of methicillin-resistant Staphylococcus aureus. Trends Microbiol. 9:486-93.

17. HOOKEY, J.; RICHARDSON, J.; COOKSON, B. 1998. Molecular typing of Staphylococcus aureus based on PCR restriction fragment length polymorphism and DNA sequence analysis of the coagulase gene. J. Clin. Microbiol. 36:1083-1089.

18. INTRAKAMHAENG, M.; KOMUTARIN, T.; PIMPUKDEE, K.; AENGWANICH, W. 2012. Incidence of enterotoxinproducing MRSA in bovine mastitis cases, bulk milk tanks and processing plants in Thailand. J. Anim. Vet. Adv. 11:655-661.

19. JACKSON, C.; DAVIS, J.; BARRETT, B. 2013. Prevalence and characterization of methicillin-resistant Staphylococcus aureus isolates from retail meat and humans in Georgia. J. Clin. Microbiol. 51(4):11991207.

20. JONES, T.; KELLUM, M.; PORTER, S.; BELL, M.; SCHAFFNER, W. 2002. An outbreak of communityacquired foodborne illness caused by methicillinresistant Staphylococcus aureus. Emerg. Infect. Dis. 8(1):82-84.

21. KLUYTMANS, J.; van LEEUWEN, W.; GOESSENS, W.; HOLLIS, R.; MESSER, S.; HERWALDT, L.; BRUINING, H.; HECK, M.; ROST, J.; van LEEUWEN, N. 1995. Food-initiated outbreak of methicillinresistant Staphylococcus aureus analyzed by phenoand genotyping. J. Clin. Microbiol. 33(5):1121-1128.
22. MEJÍA, C.; ZURITA, J.; GUZMÁN-BLANCO, M. 2010. Epidemiology and surveillance of methicillinresistant Staphylococcus aureus in Latin America. Braz. J. Infect. Dis. 14(2):79-86.

23. MEHROTRA, M.; WANG, G.; JOHNSON, W. 2000. Multiplex PCR for detection of genes for Staphylococcus aureus enterotoxins, exfoliative toxins, toxic shock syndrome toxin 1 , and methicillin resistance. J. Clinical Microbiol. 38(3):1032-1035.

24. MOELLERING, R. 2012. MRSA: the first half century. J. Antimicrob. Chemother. 67(1):4-11.

25. MOON, J.; LEE, A.; KANG, H.; LEE, E.; KIM, M.; PAIK, Y.; PARK, Y.; JOO, Y.; KOO, H. 2007. Phenotypic and genetic antibiogram of methicillin-resistant staphylococci isolated from bovine mastitis in Korea. J. Dairy Sci. 90 (3):1176-1185.

26. NORMANNO, G.; CORRENTE, M.; LA SALANDRA, G.; DAMBROSIO, A.; QUAGLIA, N.; PARISI, A.; GRECO, G.; BELLACICCO, A.; VIRGILIO, S.; CELANO, G. 2007. Methicillin-resistant Staphylococcus aureus (MRSA) in foods of animal origin product in Italy. Int. J .Food Microbiol. 117:219-22.

27. NTC 4779. 2007. Norma Técnica Colombiana. Microbiología de alimentos y alimentos para animales. Método horizontal para el recuento de Estafilococos coagulasa positiva (Staphylococcus aureus y otras especies). Bogotá, D.C.: Instituto Colombiano de Normas Técnicas y Certificación (ICONTEC). URL Disponible desde Internet en: http://tienda.icontec. org/brief/NTC4779.pdf (con acceso el 12/11/2014).

28. OGATA, K.; NARIMATSU, H.; SUZUKI, M.; HIGUCHI, W.; YAMAMOTO, T.; TANIGUCHI, H. 2012.

Commercially distributed meat as a potential vehicle for community-acquired methicillin-resistant Staphylococcus aureus. Appl. Environ. Microbiol. 78(8):2797-2802.

29. PINCHUK, I.; BESWICK, E.; REYES, V. 2010. Review Staphylococcal enterotoxins. Toxins. 2:2177-2197.

30. ROSEC, J.; GIGAUD, O. 2002. Staphylococcal enterotoxin genes of classical and new types detected by PCR in France. Int. J. Food Microbiol. 77:61-70.

31. SHANEHBANDI, D.; BARADARAN, B.; SADIGHETEGHAD, S.; ZARREDAR, H. 2014. Occurrence of methicillin resistant and enterotoxigenic 
Staphylococcus aureus in traditional cheeses in the north west of Iran. ISRN Microbiology. 2014. 5p. doi:10.1155/2014/129580.

32. SHAHRAZ, F; DADKHAH, H.; KHAKSAR, R.; MAHMOUDZADEH, M.; HOSSEINI, H.; KAMRAN, M.; BOURKE, P. 2012. Analysis of antibiotic resistance patterns and detection of mecA gene in Staphylococcus aureus isolated from packaged hamburger. Meat Sci. 90(3):759-63.

33. SMYTH, R.; KAHLMETER, G.; OLSSON, L.; HOFFMAN. B. 2001. Methods for identifying methicillin resistance in Staphylococcus aureus. J. Hosp. Infect. 48:103107.

34. VANDERHAEGHEN, W.; CERPENTIER, T.; ADRIAENSEN, C.; VICCA, J.; HERMANS, K.; BUTAYE, P. 2010. Methicillin-resistant Staphylococcus aureus (MRSA) ST398 associated with clinical and subclinical mastitis in Belgian cows. Vet. Microbiol. 144(12):166-171.

35. VANEGAS, M.; GONZÁLEZ, L.; MARTÍNEZ, A.; BUITRAGO, F. 2008. Aislamiento y caracterización de cepas de Staphylococcus enterotoxigénicos aislados de quesos en Bogotá. Rev. MVZ Córdoba. 13(2):1288-1293.
36. VANEGAS, C.; MORENO, J.; RAMOS, V.; CHIRIVI, J.; GARZÓN, A.; ARÉVALO, S.; MARTÍNEZ, M.; GARDEAZÁBAL, P.; BAQUERO, C. 2012. Methicillinresistant Staphylococcus aureus (MRSA) isolated from Colombian foods. Bio. 2:61-67.

37. VOSS, A.; LOEFFEN, F.; BAKKER, J.; KLAASSEN, C.; WULF, M. 2005. Methicillin-resistant Staphylococcus aureus in pig farming. Emerg. Infect. Dis. 11(12):1965-1966.

38. WANG, X.; LI, G.; XIA, X.; YANG, B.; XI, M.; MENG, J. 2014. Antimicrobial susceptibility and molecular typing of methicillin-resistant Staphylococcus aureus in retail foods in Shaanxi, China. Foodborne Pathog. Dis. 11(4):281-286.

39. WEESE, J.; AVERY, B.; REID-SMITH, R. 2010. Detection and quantification of methicillin-resistant Staphylococcus aureus (MRSA) clones in retail meat products. Lett. Appl. Microbiol. 51(3):338-342.

Recibido: Octubre 27 de 2014

Aceptado: Marzo16 de 2015

Cómo citar:

Herrera A., F.; Santos B., J. 2015. Presencia de Staphylococcus aureus meticilina-resistentes en queso doble crema artesanal. Rev. U.D.C.A Act. \& Div. Cient. 18(1): 29-37. 